
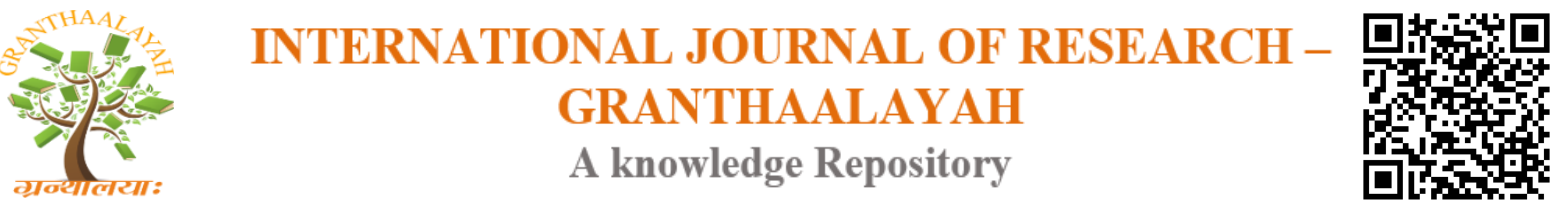

Science

\title{
RFID TECHNOLOGY: AN OVERVIEW
}

\author{
Amit Kumar Pal ${ }^{1}$, Akanksha Tripathi ${ }^{2}$, Anupam Saigal ${ }^{3}$ \\ ${ }^{1}$ Research Scholar, Bundelkhand University, Jhansi, India \\ ${ }^{2}$ Library Assistant, Shiv Nadar University, Gr. Noida, India \\ ${ }^{3}$ Librarian, Subharti Institute of Technology and Engineering Meerut, India
}

\begin{abstract}
The information technology has changed the way library professional to interact, communicate, share and acquire knowledge. However, when the computer was created it did not have features and facilities for users to interact. With the evaluation of Internet and Communication Technology, manual library has evolved into a dynamic, interactive and collaborative platform that facilitates exchange of knowledge and information among its users. RFID is the latest technology to be used in libraries and information centers for book identification, for selfcheckout and for theft detection. This paper presents an overview of RFID, it defines RFID, Components, Benefits and Limitations.
\end{abstract}

Keywords: Radio Frequency Identification; Electromagnetic Chips; RFID Vendors.

Cite This Article: Amit Kumar Pal, Akanksha Tripathi, and Anupam Saigal. (2017). "RFID TECHNOLOGY: AN OVERVIEW." International Journal of Research - Granthaalayah, 5(12), 176-182. https://doi.org/10.29121/granthaalayah.v5.112.2017.491.

\section{Introduction}

The rapid developments in information communication technologies (ICT) have given a solid foundation for revolution changes in the information handling capabilities of libraries and information centers all over the world. ICT includes acquisition, processing, storage, retrieval and dissemination of information by means of computers and communicating systems. In a dynamic and interactive academic learning environment, information communication technology also includes repro-micrographic technology, database creation and use, in addition to computer technology, digital technology, multimedia technology, network technology, barcode technology, RFID technology web technology, etc. Library automation as we see today is a computerization of library activities and application of information technology in libraries. Library automation involves total computerization library activities starting from acquisition to management and circulation to reference service, and library technology involves use of photocopier to microfilm and barcode readers' electronic security gate. Among various library technology available in computerized and information centers. RFID is the latest technology to 
be used in library or book identification or self-checkout and for sorting and conveying of library books and also for theft detection.

\section{What is RFID?}

RFID is a generic term for technologies that uses radio waves to automatic identify an object. There are several methods of identification, but most common is a unique identification number that identifies an object, and perhaps other information, on a microchip that is attached to an antenna. The antenna enables the chip to transmit the identification information to a reader. The reader converts the radio waves reflected back from the RFID tag into digital information that can be passed to computers to make use of it.

According to the harrod's librarian's glossary and reference book RFID is an alternative to bar code that uses tiny microchips in tags to hold and transmit detailed data about the item tagged ${ }^{1}$.

Dictionary for library \& information science defines RFID as the use of microchips to tag library materials and library card, enabling users to check out items by walking through a self - service station equipped with an antenna that emits low frequency radio waves ${ }^{2}$.

\section{Need for RFID}

- Multiple books can be issued simultaneously.

- Unique id of the RFID tag prevents counterfeiting.

- Automated material handling using conveyor \& sorting systems.

- Multiple books can be issued simultaneously.

- Unique id of the RFID tag prevents counterfeiting.

- Automated material handling using conveyor \& sorting systems.

\section{Components of RFID Systems}

A comprehensive RFID system has four components:

\subsection{RFID Tags (Or Transponder)}

The chip and the antenna together are called RFID tag (or transponder). These are paper-thin smart labels which are electronically programmed with unique information. Tags are the electronic chips consisting of an integrated circuit and antenna coil that communicates with a reader by means of a radio frequency signal. These tags are available as labels with adhesive backings and ability to reel through a label printer. After sticking RFID label on the book, its vital bibliographical data, including accession number is registered in the chip of the label. This function allows writing such information on chip either from the library database or by scanning existing barcode labels and helps to identify each book. Two types RFID tags are available viz. Active or passive. Passive tags do not have there on power supply so the device is quite small. These have practical read ranges that vary from about $10 \mathrm{~mm}$ up to about 5 meters. Active RFID tags, on the other hand, must have a power source and may have longer ranges and larger memories than passive tags as well as ability to store additional information send by the 
transceiver. Active RFID tags can be about the size of a coin and have practical ranges of tens of meters, and a battery life up to several years. Many libraries are making use of passive tags because of their lower cost and appropriate size. The tags can be read at a distance of up to two feet by each of two parallel exit sensors. The devices used for circulation are usually called "readers" while the ones used at building exits are usually called "sensors".

\subsection{RFID Readers}

RFID readers or receivers are composed of radio frequency module, a control unit and an antenna to interrogate electronic tags via radio frequency (RF) communication. A system includes several different kinds of readers, also known as sensors when installed at library exits. These are radio frequency devices designed to detect and read tags to obtain the information stored there on. The reader powers an antenna to generate an RF field. When a tag passes through the field, the information stored on the chip in the tag is decoded by reader and sent to the server which, in turn, communicates with the automated library systems when the RFID system is interfaced with it. In a typical library application, RFID readers can be installed at various strategic places to support different function that RFID tags can perform.

\subsection{Some of Typical Installations Could Be}

- Workstation designed specifically for library staff to facilitate the smooth handling of books and other material having RFID labels/tags.

- The security gets with theft detection system. Any item that has not been checked-out either by staff station or self-check-out station will be detected as it goes past these pedestals.

- Self service station with provision for checking out books independently by borrower without any intervention of library staff. The theft detection system of the smart label for the book is deactivated to enable smooth passage from the security gate.

- "Drop box" where returned books are placed through suitable slits by users themselves. As books are return through the book drop facilities located suitably in a library, the smart label are automatically read, and both user record and library database gets updated.

\subsection{Antenna}

The antenna produces radio frequency waves to transmit signal that activate the transponder. Antenna is the channel between the tag and the reader, which controls the system's data acquisition and communication. The electromagnetic field produced by an antenna can be constantly present when multiple tags are expected continually. Antennas can be built into a doorframe to receive tag data from person's things passing through the door.

\subsection{Server/Docking Station}

The server is the heart of some comprehensive RFID systems. It is the communications gateway among the various components. It receives the information from one or more of the readers and 
exchanges information with the circulation database. Its software includes the apis (applications programming interface) necessary to interface it with the automated library system.

\section{How RFID System Works in Library}

The technology works through flexible, paper-thin smart labels (RFID tags), which allows it to be placed inconspicuously on the inside cover of each and every document in a library's collection and on the other collection like CDs, DVDs etc. Complete information about each document is entered into the software installed in server or docking station. Now whenever a user brings the book for issue/return purpose, the RFID reader from the tag reads the information pertaining to the book and transmit the data into the software book is smoothly issued in a few seconds with a minimum of manual intervention. As the user takes the book outside the library the antenna placed at the exit gate automatically read the information contained on the RFID tag to verify whether the book is properly issued or not. In case the book is not issued to the user as per the library norms or it is being stolen from the library, the antenna senses it and give an instant alert. Thus the technology results in successful theft reduction of documents. The technology is also used for stock taking/inventory management purpose.

\subsection{Benefits of RFID System}

Benefits of RFID technology in library are categories as follows:

\subsubsection{Benefits to Library Management}

- Uncompromised security within the library.

- Efficient collection management system (can be located suitably and made 24x7).

- Uncompromised collection security.

- Flexible staff schedules.

- Labor saving methods free the staff to help customers.

- Higher customer/patron satisfaction levels.

- Improved inter-library cooperation.

- Better preservation of inventory because of less. Handling by staff.

- Same security and labeling formats for all items such as books, CDs and DVDs, hence better management of databases

\subsubsection{Benefits for Library Staff}

- Time saving devices free them to help customer better

- Labor saving devices free them from doing repetitive, physically stressful tasks.

- Can have flexible working schedules

\subsubsection{Benefits for Library Patrons}

- Self-check-in and self-check-out facilities

- Check-in and check-out of all types of items (books, audio tapes, video tapes, CDs, DVDs, etc.) At the same locations 
- More staff available for assistance

- Quicker service such as payment of fees, fines, etc.

- Better inter-library facilities, more efficient reservation facilities, etc.

- Faster and accurate re-shelving means patrons can find items where they should be, hence quicker and more satisfying service

- Height adjustable self-check-in/out tables are liked by children and physically disabled persons who use the library

\subsubsection{RFID Vendors in India}

There are many vendors of RFID components all over the world and nowadays India is also producing RFID components. A list of some of the RFID vendors with presence in India and Indian sub-continent is given below ${ }^{5}$ :

- 3M Library Systems, New Delhi,

- R.S. Barcodes, New Delhi

- Total IT Solutions, New Delhi

- TS Informatics, Delhi

- Libsys Corporation, Gurgaon

- Netlink Information Systems, Gurgaon

- Idcube Identification Systems, Noi Noida Da

- HCL Infosystems, Noida

- VTLS Software, Noida

- Bartronics India, Hyderabad,

- Capgemini India, Chennai,

- Grandeur Technologies, Chennai

- Green Futurz Software Solutions Chennai

- Modular Technologies India, Chennai

- Rapid Radio Solution Ahmedabad

- RFID Infotech, Mumbai

- I-Tek, Pune

\section{Limitation of RFID Systems}

\subsection{High Cost}

The major limitation of RFID technology is its cost. While the readers and sensors used to read the information are costing between Rs. 100,000/- to 150,000/- a server costing much as Rs. 500,000/- to 600,000/- and the tags cost Rs. 20 to Rs.25 each.

\subsection{Easy to Deceive to the Technology}

It is possible to compromise an RFID system by wrapping the protective material in two to three layers of ordinary household foil to block the radio signal. It is also possible to compromise and 
RFID system by placing two items against one another so that one tag overlays another. That may cancel out the signals. This requires the knowledge of the technology and careful alignment.

\subsection{Removal of Tags}

RFID tags are typically affixed to the inside back cover and are exposed for removal. This means that there would problems when users become more familiar with the role of the tags. In Indian library, it is the major challenge to keep the tags intact.

\subsection{Exit Sensor (Reader) Problems}

While the short range readers used for circulation charge and discharge and inventorying appear to read the tags $100 \%$ of the time, the performance of the exit sensors is more problematic. They must read tags at up to twice the distance of other readers. The author knows of no library that has done a before and after inventory to determine the loss rate when RFID is used for security.

\subsection{Fear To Invade User Privacy}

Privacy concerns associated with item-level tagging is another significant barrier to library use of RFID tags. The tags contain static information that can be relatively easily read by unauthorised tag readers. This allows for privacy issues describe as "tracking" and "hot listing".

Tracking refers to the ability to track the movements of a book (or person carrying the book) by "correlating multiple observations of the book's "bar code" or RFID tag. Hot listing refers to the process of building a database of books and their associated tag numbers (the hot list) and then using and unauthorised reader to determine who is checking out items in the hot list.

\subsection{Reader Collision}

The signal from one reader interfering with the signal from another where coverage overlaps is reader collision. One way to avoid the problem is to use of technique called time division multiple access, or TDMA. In simple terms the reader are instructed to read at different times, rather than both trying to read at the same time. This ensures that they don't interfere with each other. But it means any RFID tag in an area where two readers over laps will be read twice.

\subsection{Tag Collision}

Another problems reader have is reading a lot of chips in the same field. Tag clash occurs when more than one chip reflects back a signal at the same time, confusing the reader. Different vendors have developed different systems for having the tags respond to the reader one at a time. Since they can be read in milliseconds, it appears that all the tags are being read simultaneously.

\subsection{Lack of Standard}

The tags used by library RFID vendors are not compatible even when they conform to the same standards because the current standards only seek electronic compatibility between tags and 
readers. The pattern of encoding information and the software that processes the information differs from vendor to vendor; therefore, a change from one vendor's system to the other would require retagging all items or modifying the software.

\section{Conclusion}

Several libraries have successfully installed the RFID solutions in Indian. The products of many manufactures of library rho systems are available in India through their business associates or direct. RFID technology has been used in a number of Indian libraries like : Anna University Chennai, Punjab University Chandigarh, University of Pune Library (Maharashtra), Nirma University Ahmadabad (Gujarat), JIM Indore, IIM Lucknow, Indian Institute Science Bangalore, IIT Library Chennai, IIT Library Delhi, IIT Kharagpur, National Social Science Documentation Centre New Delhi, National Chemical Laboratory Pune, National Institute of Rourkela (Orissa), NIT Surat (Gujarat), Parliament Library New Delhi, Bank of Baroda Mumbai etc. RFID is a technology that is sparking interest in the library community because of its applications that promise to increase efficiency, productivity and enhance user satisfaction. Its application increases productivity, and eliminates human error, improves speed of operations and services. The main barrier to implement the RFID technology is cost justification for the application the magnitude of expected improvement of the introduction of the technology in a library is directly proportional to the size of it's a collection, the number of users, and the number of transactions per day.

\section{References}

[1] Ray, Pritherch (2005). Harrod's Librarian's Glossary And Reference Book. England: Ashagate.

[2] Reitz, Joan M. (2004). Dictionary For Library And Information Science. Chennai: Rain Tree.

[3] Chaurasia, Neeraj Kumar And Chaurasia, Pankaj (2012). Implementation Of An Innovative RFID Technology In Central Library Iit Delhi. In R. G. Prasar (Ed), Ict Based Information Management In Indian Library New Delhi: Bookwell. 129-153.

[4] RFID On Line Access 22-03-2013 Http://Www.Rfid4u.Com/Downloads/Library\%20Automation\%20Using\%20 RFID.Pdf

[5] Vasistha, Seema (2009), Roadmap For RFID Implementation In Central Library, Pec University Of Chandigarh. In Proceedings Of International Conference On Academic Library (Ical 2009). New Delhi: University Of Delhi .300-306.

\footnotetext{
*Corresponding author.

E-mail address: amipal83@gmail.com/aakankshatripathi1@gmail.com/anupam_saigal@ rediffmail.com
} 